ISSN 1112-9867

Available online at

http://www.jfas.info

\title{
COMPARATIVE STUDY OF THE NOISE GENERATED BY THE MOTO-COMPRESSOR AND THAT GENERATED BY THE TURBO-COMPRESSOR
}

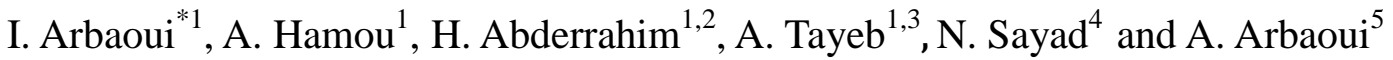 \\ ${ }^{1}$ Environment and Materials studies' laboratory of Physics Department, Exact and Applied \\ Sciences Faculty of Oran University 1 Ahmed Ben Bella \\ ${ }^{2}$ Oran's Research and Formation Hydrometeorology Institute, Algeria \\ ${ }^{3}$ Hygiene, Security and Environment Department LRP Sonatrach, Algeria \\ ${ }^{4}$ Faculty of Mathematics and Computer Science, University of Science and Technology \\ mohamed boudiaf, Algeria \\ ${ }^{5}$ Department of Hydraulics, University of Bechar
}

Received: 04 July 2017 / Accepted: 10 December 2017 / Published online: 01 January 2018

\begin{abstract}
The fundamental aim of this study is to compare between the noise generated by the moto-compressor and the noise generated by the turbo-compressor operating $24 \mathrm{H} / 24 \mathrm{H}$ on the continuous function mode; these two machines make part of the equipment of the GP1Z, a factory of hydrocarbon treatment. To attain the principal objective of this study we divided our work into two parts, in the first part we followed and evaluated the average level of the noise emitted by the two machines, whereas in the second part we studied the noise propagation emitted by the two machines and its impact on the generation of the noise. The results obtained from this study demonstrate that the noise generated by the turbo-compressor is higher than the noise generated by the moto-compressor.
\end{abstract}

Keywords: noise; moto-compressor; turbo-compressor; noise maping.

Author Correspondence, e-mail: arbaoui.iliace@gmail.com

doi: http://dx.doi.org/10.4314/jfas.v10i1.15 


\section{INTRODUCTION}

Noise is unwanted sound from activity in certain rate and time, which can cause human health problems and disturbs environmental comfort [1 and 2], Turbo-compressor (TC) are well known machines with a development of near a hundred years, Centrifugal compressors of industrial systems use mechanical energy to compress the working fluid [3].

Nowadays, there is a great concern about noise in city-based and industrial areas [4-17]

The noise generated from operating wind and gas turbines [18-35] is classifiable as an aerodynamic or a mechanical sound as a whole. Aerodynamic sound is generated from the blade passing through the air, and mechanical sound is emitted by some equipment in the nacelle [36].

Global warming and greenhouse gas emissions are a great concern. To reduce these emissions, there is a global trend towards cleaner energy sources [37]. In our study we studied the case of two compressors with two different coupling, the first coupling with a gas turbine and the second coupling with an electric motor, the gas turbine functions by the combustion of fuel gas causing greenhouse gas emissions and noise pollution, contrary to that, the electric motor is not polluting like the turbine, it is for this reason that we made a comparative study between the noise generated by the turbo-compressor and that generated by the motor-compressor. These latter machines are among the first sources that cause the problem of noise of industrial origin, several studies have been carried out in the world to treat the industrial noise problem [38], Noise is often one of the environmental variables seem more difficult to guarantee full compliance with legal limits in complex industrial situations and/or in other multi-source environments [39].

In addition to previously announced objectives, this study examined also the environmental impact of noise generated by both of the moto-compressor and the turbo-compressor in large, based on situ measurements of sound pressure levels and noise mapping.

\section{MATERIALS AND METHODS}

There no study whatever it is, that could get credibility without having field measurments, therefore we chose an important site (GP1Z) as a first step. After moving there as a second 
step, we made synchronis measurments for both the turbo-compressors and the moto-compressors during 4hours(8h-12), we chose this time because the output of the compressors is maximal during this period of the day, and to get credible results; in the third stage we compared between the results of the noise measurments of both of the compressors. Finally and to know the environmental impact of the noise generated by the turbo-compressors and that generated by the moto-compressors we made a noise mapping.

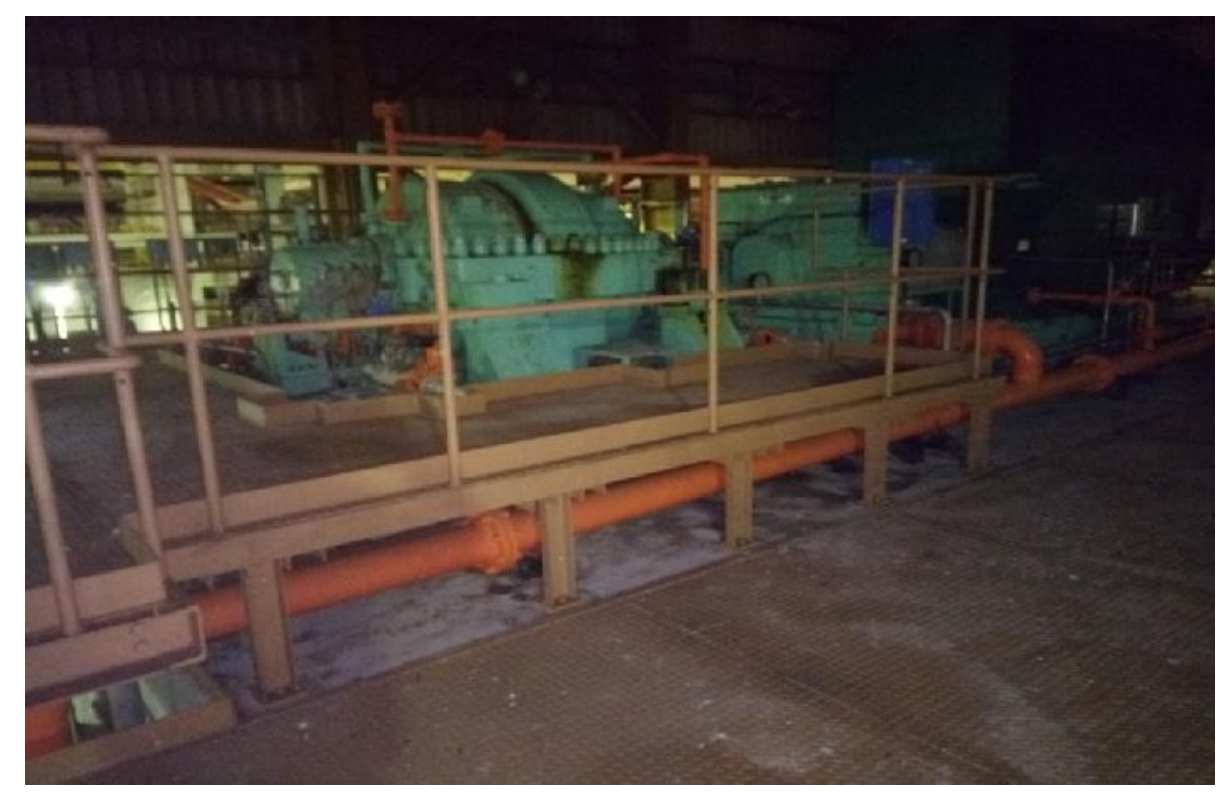

Fig.1.Turbo-compressor of sequence 100

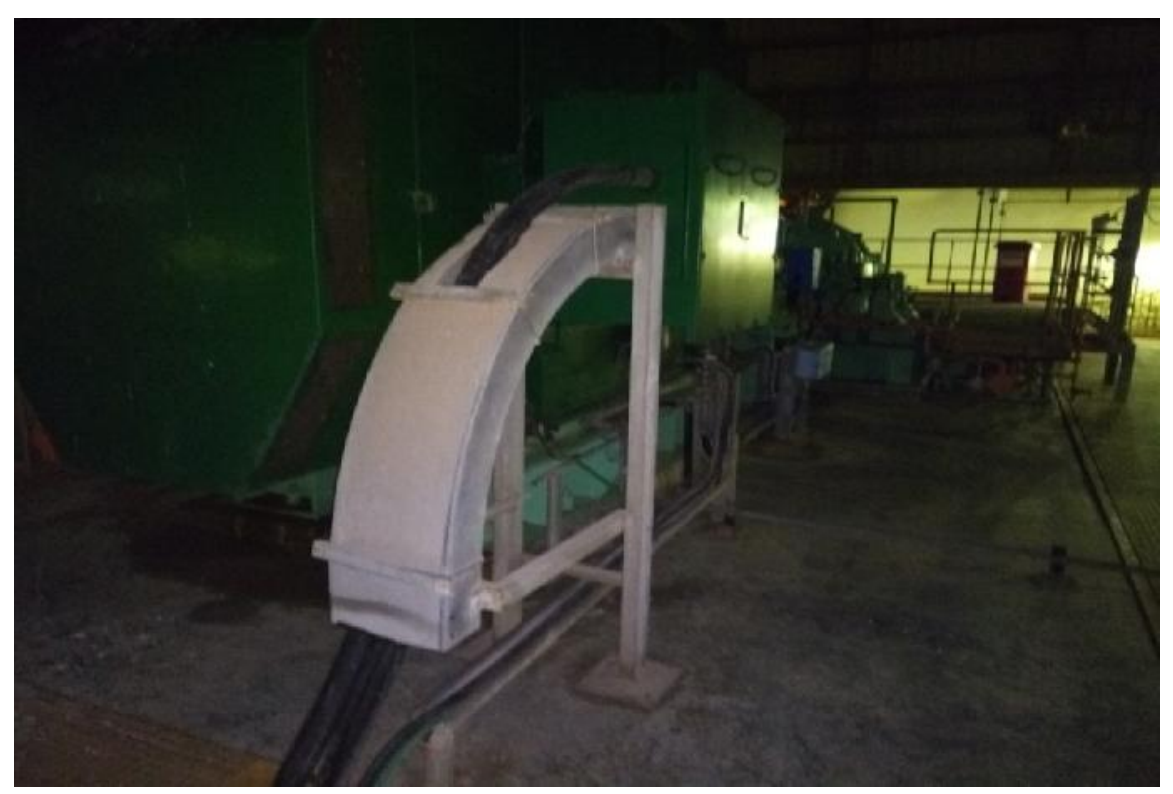

Fig.2. Moto-compressor of sequence 600 


\subsection{Site selection}

To achieve the objective of the current study which is to compare btween the noise generated by the moto-compressors and that generatd by the turbo-compressors ,so, we chose the chemical plant GP1/Z, that contains several types of compressors. As shown in figures 03 and 04.

The plant GP1Z is situated in the west-north of Algeria in the industrial zone of Arzew,the province of Oran,the surface of this plant is 120 hectars, it is classified among the best african plants concerning chemical industries, the fundamental objective of this plant is to separate and transform the GPL to produce propane and butan in order to supply the algerian market and to export abroad.

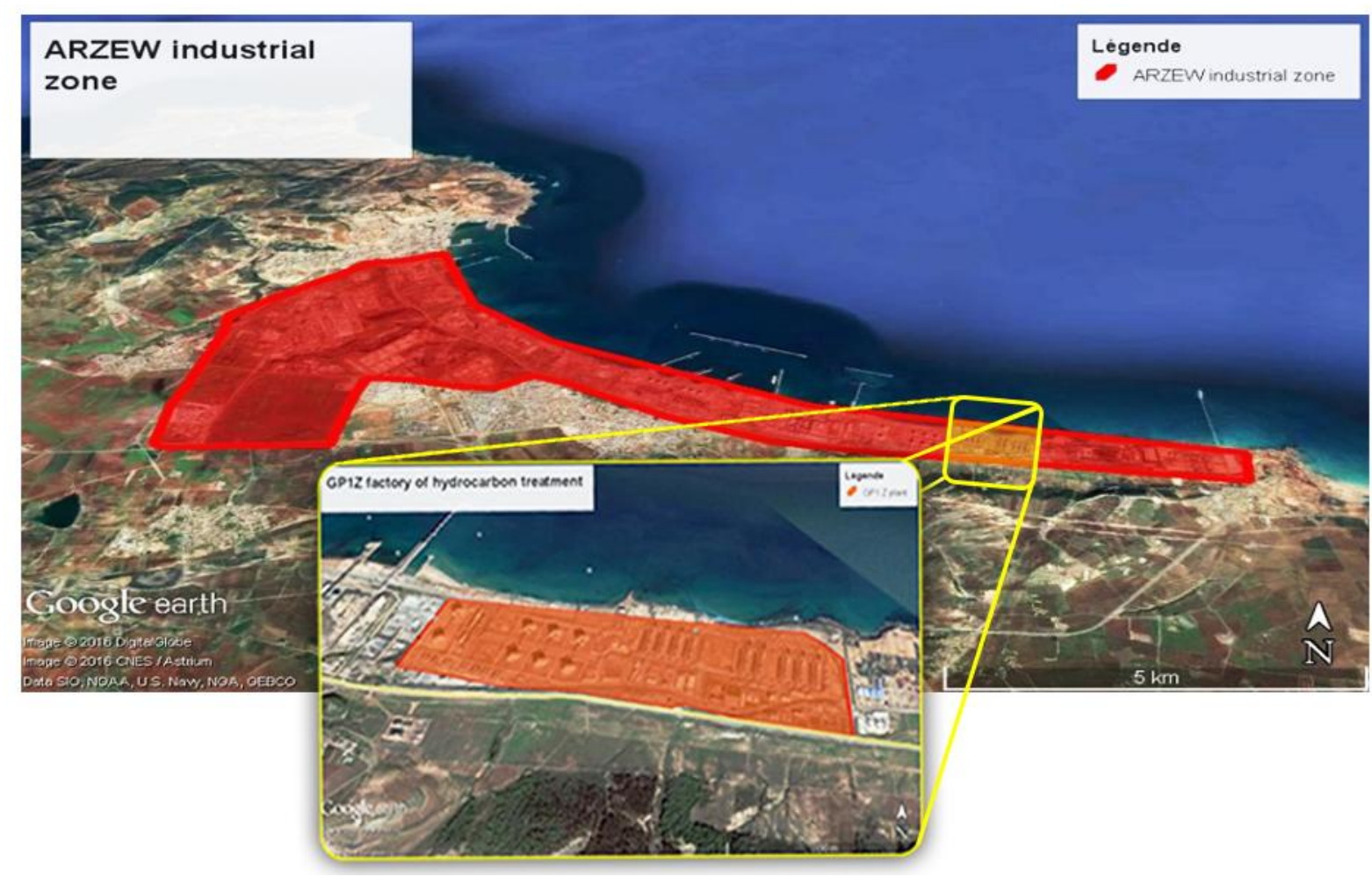

Fig.3. Arzew industrial zone's geographical location and GP1Z plant's geographical location. 


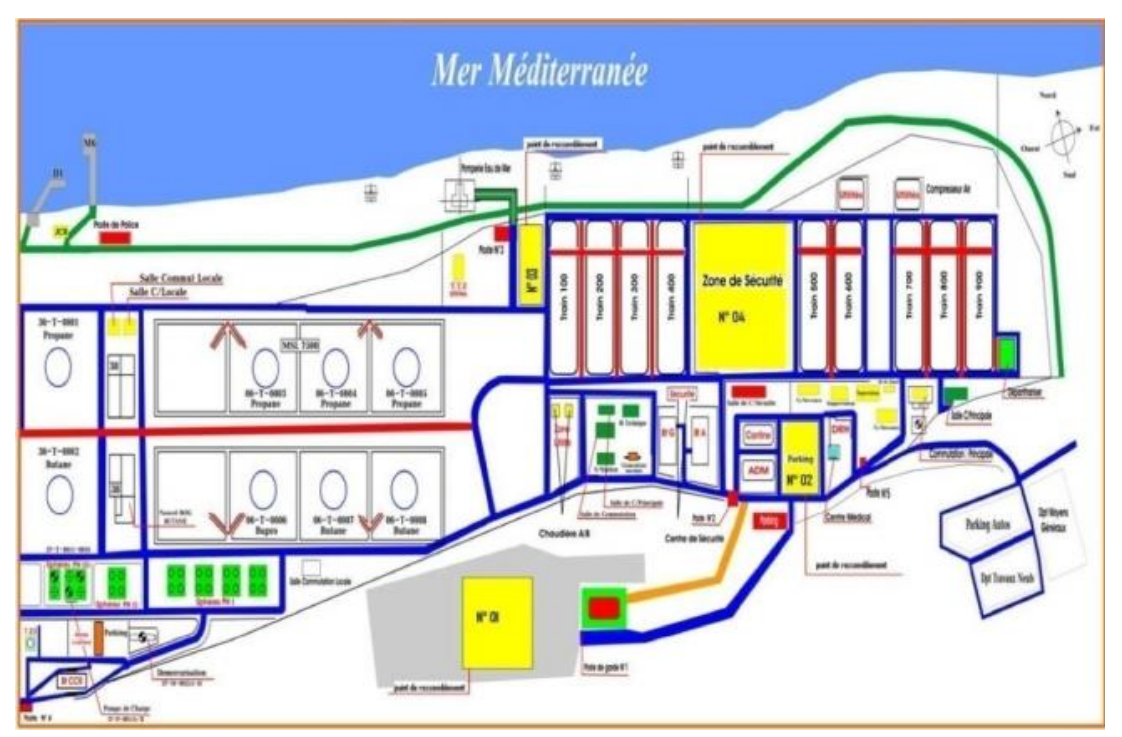

Fig.4. General ground plan on the main installations GP1 / Z[40]

\subsection{Materials used}

The Sound level meter used is Roline RO-1350, $94 \mathrm{~dB}$ calibrations, with "Fast" temporal balance and "A" frequency.

Since the introduction of the EU ambient noise directive, strategic noise mapping has been used as a tool for noise policy in many European countries [41]. For this reason we have carried out the mapping of the noise in order to prove the impact of the turbo-compressor and moto-compressor on noise pollution; we have made a noise mapping of GP1/Z plant. As an indication, Several simulator have been adopted for making noise maps[42-47] such as ; Sound City, CadnaA, OUIE2000, DBlink (Industry) and IMMI dB Vib instrumentation [45], we chose the CODE-TYMPAN, which is adapted to industrial noise as a tool for interpreting our results.

\section{RESULTS AND DISCUSSION}

The figures 05 and 06 demonstrates that the recorded level of noise generated by the turbo-compressor during four hours (from 8:00 to 12:00) of continued work is very high and attains the $95,1 \mathrm{~dB}(\mathrm{~A})$; the origin of this noise is fundamentally due to the gas turbine which is feed by fuel gas, which enters the room of combustion to produce vigorous gas of exhaust, this energy of the fluid transforms into a rotating mechanical energy on a shaft allowing a 
compressor to be driven. The compressor is linked to the turbine through a common shaft; the principal role of the compressor is to compress the gas.

Several origins of noise can be distinguished in the turbo compressor system:

- It's evident that a small fraction of this energy is converted to an acoustic energy, it can propagate into the whole system and be manifested as noise, and the vibration of the body can also contribute to the generation of noise.

- The vibration of the compressor's components or surfaces because of the variations of the pressure generated in the fluid.

- The unbalanced rotors, the rubbing of the shaft, the partition of the vibrating pipes.

The figures 7 and 8 represent the level of noise on average recorded in moto-compressors during four hours of continued work (8:00 to 12:00), a moto-compressor is a combination of an electrical engine and a compressor, the engine transforms the electrical energy to a mechanical energy to rotate the compressor; the total emission of noise in the moto compressors is considered to be a combination of the two sources of noise not correlated together: magnetic and mechanical. The noise of mechanical origin in a moto-compressor is created by several elements:

-the function of the cooling fan creates the majority of the mechanical noise.

-the interaction between the shaft and the bearing contributes also to the generation of noise.

The noise of the mechanical origins is an audible noise coming from the vibrations due to the magnetic forces, and it stops consequently when the machine is switched off, this type of noise depends on the shaft's charge, the voltage, the current, the frequency, the enrolment's parameters, and the groove's geometry, etc. 


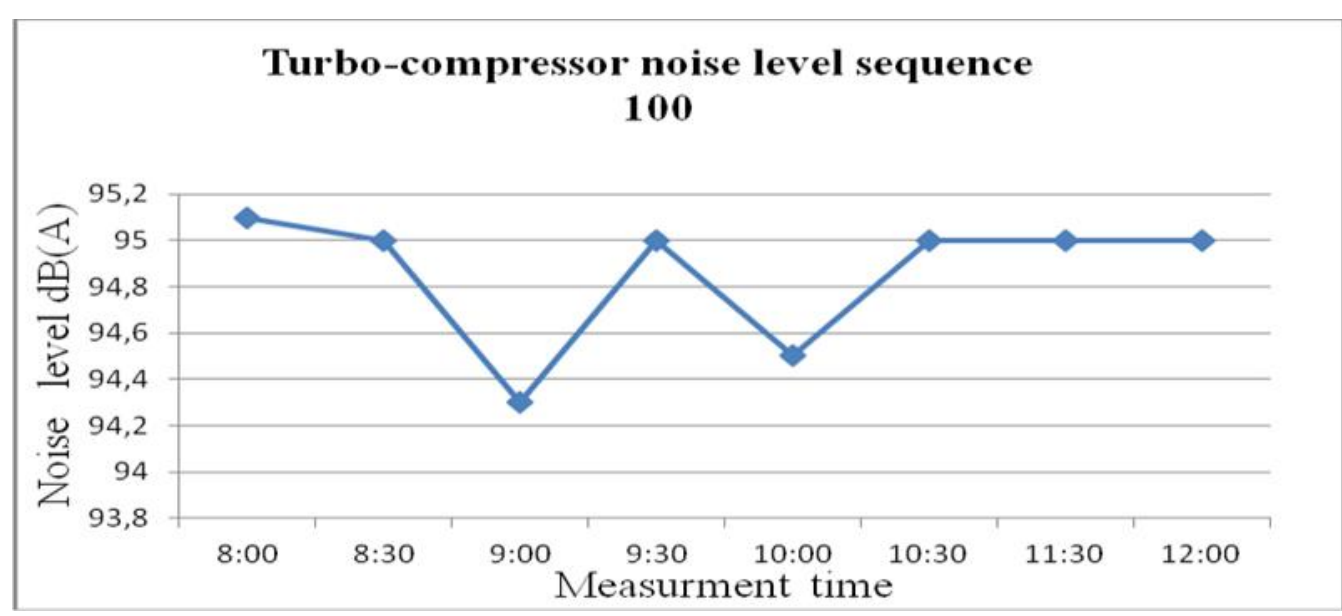

Fig.5. Noise level recorded in sequence 100

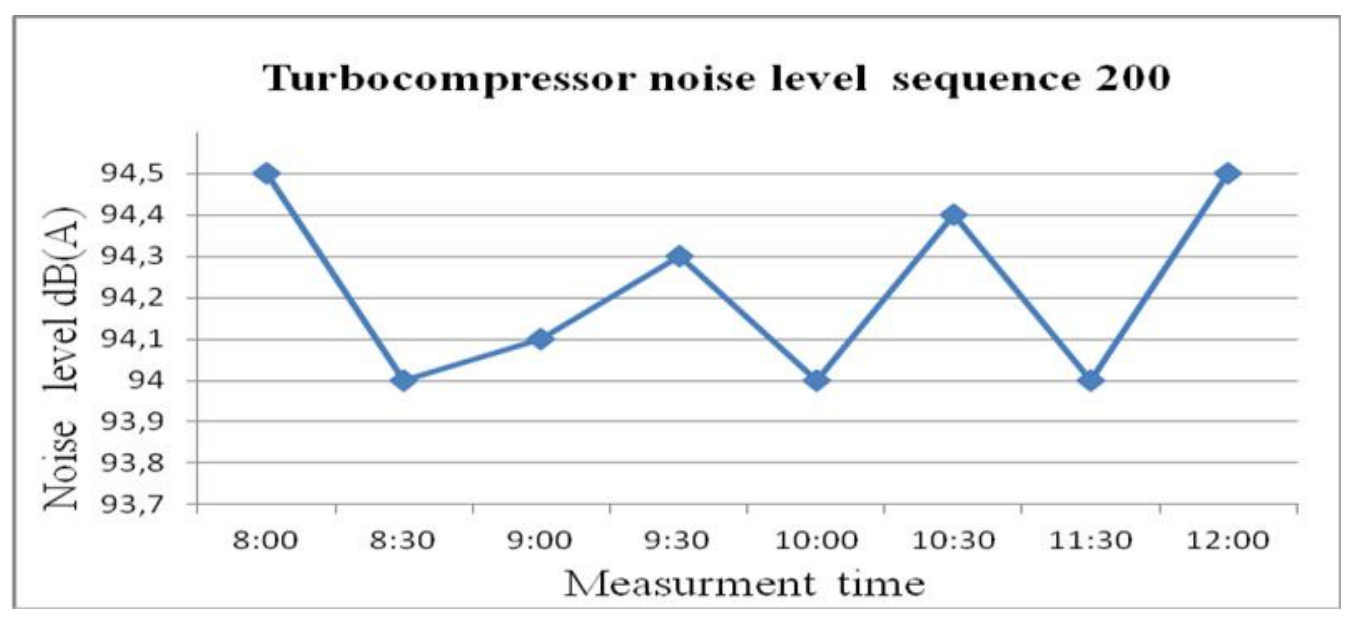

Fig.6. Noise level recorded in sequence 200

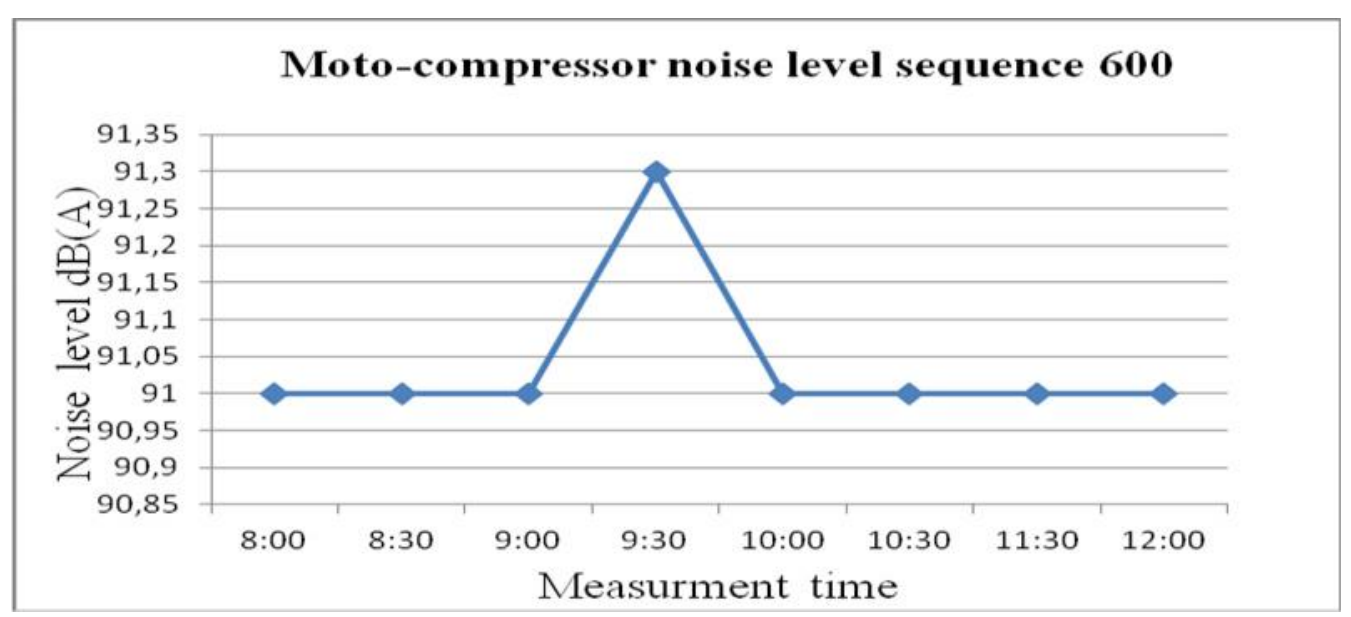

Fig.7. Noise level recorded in sequence 600 


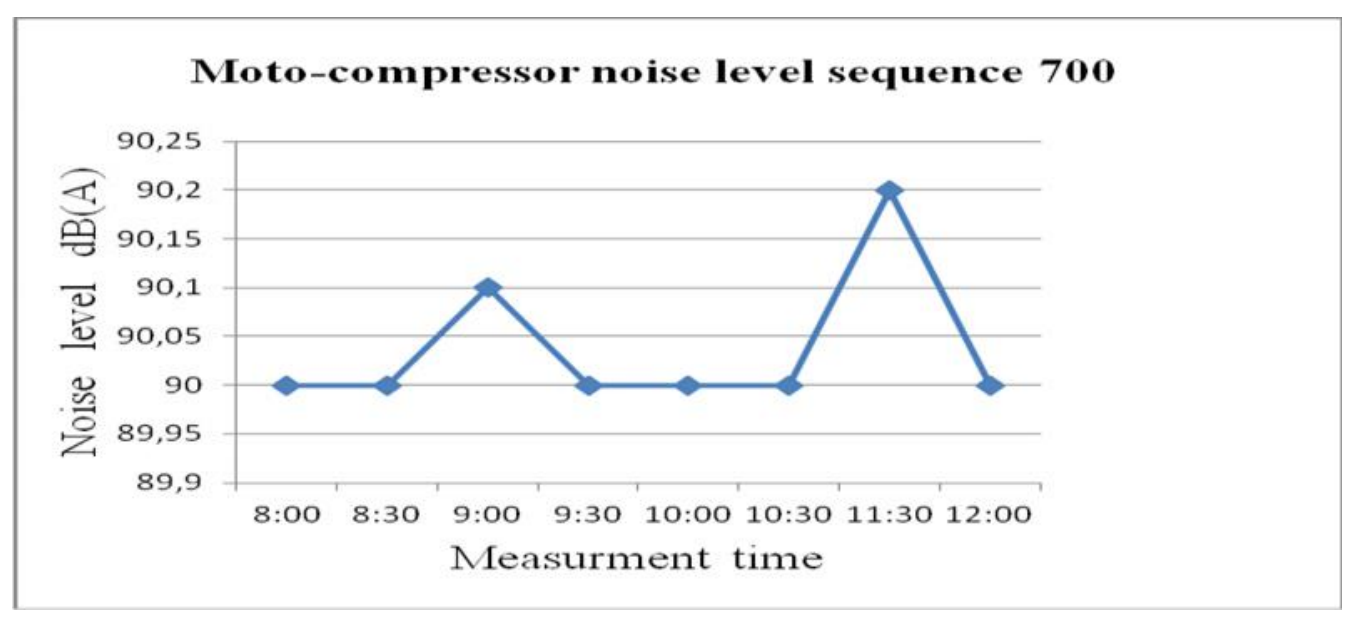

Fig.8. Noise level recorded in sequence 700

\subsection{A comparison between the noise level generated by the turbo compressors and that} generated by the motor compressors:

The histogram below represents a comparison between the noise generated by the turbo-compressor and the noise generated by the mto-compressors. These results demonstrate that the turbo-compressor is noisy compared to the mto-compressor.

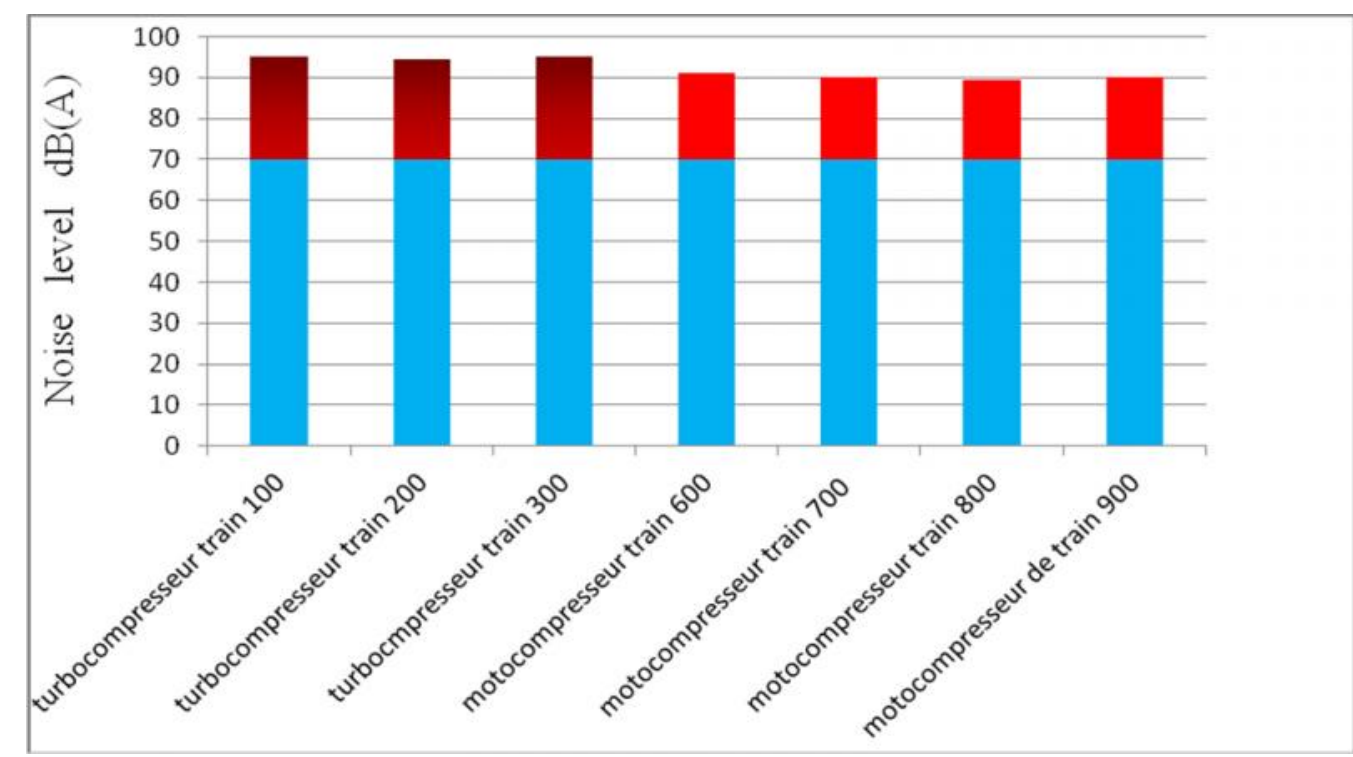

Fig.9. Histogram of comparison between the noise generated by the turbo-compressor and the noise generated by the Moto-compressor 


\subsection{The impact of the noise generated by both the moto-compressor and the turbo} compressor on the increasing of noise pollution

The complex GPLZ contains much equipment that contributes to noise pollution (pumps, Chaudières, fans......), but the noisiest equipment in this complex is the motor compressors and the turbo compressors, and to confirm that result, we have made field measurement to all the complex's machines.

In order to prove to huge impact of the turbo-compressors and the moto-compressors on noise pollution ; we have made a noise mapping (figure 10), in the first stage, we have measured the noise level generated by all the other machines of the complex(without the compressors), we have noticed that the noise level has significantly decreased, in the second stage we have introduced the compressors' data again with all the other machines of the complex and measured the noise generated by the whole complex's equipment, the results we have got form a simple comparison between the results in the two stages specifies the great effects of the turbo-compressors and the moto-compressors on the generation of noise pollution.

As far as the noise mapping is concerned, the comparison between the noise level with and without the turbo-compressors and the moto-compressors, we notice that the compressors have an important effect on the generation of noise pollution:

-The global noise average has increased

-The surface of the noise spreading has enlarged outside the complex, this increasing and enlargement of the noise has deep negative effects on the complex's neighboring inhabitants From the results of the noise mapping, we conclude that the noise generated by the moto-compressors and that generated by the turbo-compressors has a great impact on the environmental noise generation inside and outside the plant, we could also observe that the propagation of the noise's surface is increasing if we take the noise in consideration, then we can talk about its impact on health of the workers inside the plant for 8 hours a day and on the health of the neighboring inhabitants who are exposed to a higher rate of that noise. 


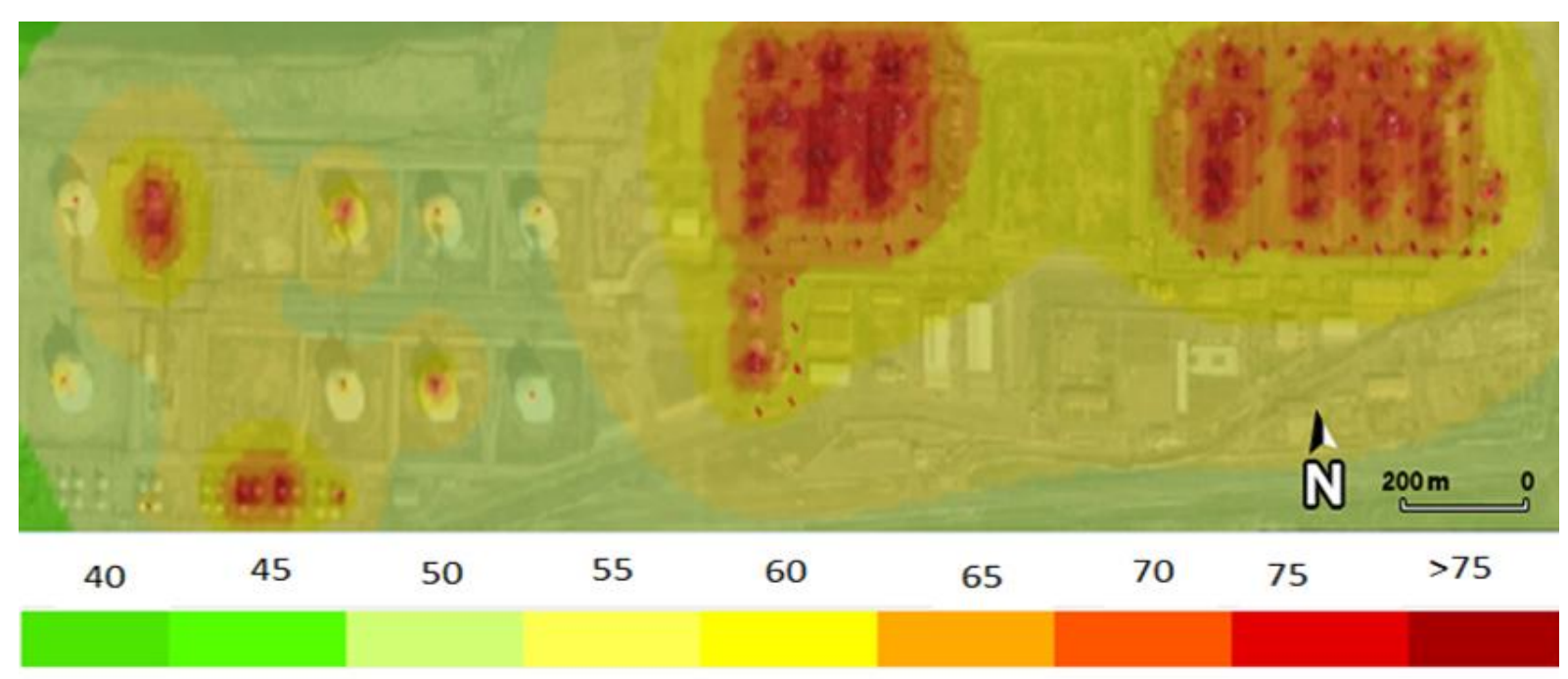

Fig.10.General noise mapping of the GP1Z plant

\section{CONCLUSION}

From all results obtained in this study we concluded that:

1-The turbo-compressors is noisier than the motor compressor.

2-The noise level of the turbo-compressor of the sequence 100 and 200 is so high and intense, it's unstable and varies between $95.6 \mathrm{~dB}$ (A) and $94.3 \mathrm{~dB}$ (A) during four hours of measurement by a continued regime.

3-The noise levels of the moto-compressor of the sequence 600-700 is less high compared to that of the turbo compressor(100-200),moreover it's almost steady on the value $91 \mathrm{~dB}$, by contrary, the noise level of the noise generated by a turbo compressor 100-200 varies by an aleatory manner.

To this end, we recommend that those who are responsible for changing the turbo-compressor by moto-compressors to reduce the noise level and the percentages of gases $\left(\mathrm{CO}_{2}, \mathrm{NOx}\right.$, etc.) escaping from the torches. This will also save gas, reduce flue gas emissions and improve environmental working conditions. But this idea requires an economic study in order to take the economic aspect on consideration. So concluded from the steps above, any future intention to solve such kind of industrial solution inside such plants should take the compressors quality improvement in consideration. 


\section{ACKNOWLEDGEMENTS}

The author is thankful to the director of the environment and materials studies' laboratory of Oran's university 1 Ahmed Ben Bella and SONATRACH authorities for support and facilities provided by them to achieve and complete this study.

\section{REFERENCES}

[1]: The Ministry of Environment of the Republic of Indonesia. The Decree of the Minister of Environment Number Kep-48/MENLH/11/1996 on the Standard noise level (in Indonesia); 1996.

[2]: Nur Indrianti, Nandyan Banyu Biru, and Tri Wibawa, The development of compressor noise barrier in the assembly area (Case study of PT Jawa Furni Lestari), 13th Global Conference on Sustainable Manufacturing - Decoupling Growth from Resource Use, Procedia CIRP 40 ( 2016 ), Pages $705-710$

[3]: Silviu Ionescu, Valentin Silivestru, Nicolae Enescu, Ioan Magheti , Adina Ionescu, Experimenal approaches to reduce noise at source for a centrifugal compressor, U.P.B. Sci. Bull., Series D, (2011), Vol. 73, Iss. 3, Pages 32-40.

[4]: Schultz TJ. Synthesis of social surveys on noise annoyance. J Acoust Soc Am (1978);64(2), Pages 377-405.

[5]: Saadu AA, Onyeonwu RO, Ayorinde EO, Ogisi FO. Community attitudinal noise survey and analysis of eight Nigerian cities. Appl Acoust (1996); 49(1) Pages 49-69.

[6]: Belojecic G, Jakovljecic B, Aleksic O. Subjective reactions to traffic noise with regard to some personality traits. Environ Int (1997); 23, Pages 221-6.

[7]: LamWHK, TamML. Reliability analysis of traffic noise estimates in Hong Kong. Transp Res D, (1998);3(4), Pages 239-48.

[8]: Arana M, Garcia A. A social survey on the effects of environmental noise on the residents of Pamplona, Spain. Appl Acoust (1998); 53(4), Pages 245-53.

[9]: Maschke C. Preventive medical limits for chronic traffic noise exposure. Acustica ; 85(1999): Pages 444-8.

[10]: Zannin PHT, Diniz FB, Calixto A, Barbosa W. Environmental noise pollution in 
residential areas of the city of Curitiba. Acustica (2001); 87, Pages 625-8.

[11]: Zannin PHT, Diniz FB, Calixto A, Barbosa W. Environmental noise pollution in the city of Curitiba, Brazil. Appl Acoust (2002); 63, Pages 351-8.

[12] : Morillas JMB, Gómez RVG, Escobar VG, Sierra JAM, Vidal CT, Bueno LA, et al. Presentación de una encuesta para la realización de estudios sociales sobre el impacto del ruido urbano, Presentation of a survey for social studies on the impact of urban noise. Rev Acust (2002) ; 33, Pages 27-31.

[13]: Zannin PHT, Szeremetta B. Avaliação da poluição sonora no parque Jardim Botânico de Curitiba, Paraná, Brasil (Evaluation of noise pollution in the Botanical Gardens of Curitiba, Paraná, Brazil. Cad Saude Publica 2003; 19(2), Pages 683-6.

[14]: Paz EC, Ferreira AMC, Zannin PHT. Comparative study of the perception of urban noise (Estudo comparativo da percepção do ruído urbano). Rev Saude Publica (J Public Health) 2005;39(3), Pages 467-72.

[15]: Zannin PHT, Sant 'Ana DQ. Noise mapping at different stages of a freeway redevelopment project—a case study in Brazil. Appl Acoust 2011; 72(8) Pages 479-86. [16]: Guedes ICM, Bertoli SR, Zannin PHT. Influence of urban shapes on environmental noise: a case study in Aracaju Brazil. Sci Total Environ 2011; 412 Pages 66-76.

[17]: Zannin PHT, Engel MS, Fiedler PEK, Bunn F. Characterization of environmental noise Based on noise measurements, noise mapping and interviews: a case study at a university Campus in Brazil. Cities 2013; 31 Pages 317-27.

[18]: W.Y. Liu, A review on wind turbine noise mechanism and de-noising techniques, Renewable Energy, Volume 108, August 2017, Pages 311-320.

[19]: Fei Qu, Jian Kang, Effects of built environment morphology on wind turbine noise exposure at building façades, Renewable Energy, Volume 107, July 2017, Pages 629-638. [20]: Fredric Ottermo, Erik Möllerström, Anders Nordborg, Jonny Hylander, Hans Bernhoff, Location of aerodynamic noise sources from a $200 \mathrm{~kW}$ vertical-axis wind turbine, Journal of Sound and Vibration, Volume 400, 21 July 2017, Pages 154-166 
[21]: Christoph Pilger, Lars Ceranna, The influence of periodic wind turbine noise on infrasound array measurements, Journal of Sound and Vibration, Volume 388, 3 February 2017, Pages 188-200

[22]: P. Gallo, L. Fredianelli, D. Palazzuoli, G. Licitra, F. Fidecaro, A procedure for the assessment of wind turbine noise, Applied Acoustics, Volume 114, 15 December 2016, Pages 213-217

[23]: P. Gallo, L. Fredianelli, D. Palazzuoli, G. Licitra, F. Fidecaro, A procedure for the assessment of wind turbine noise, Volume 114, 15 December 2016, Pages 213-217

[24]: Obrad Anicic, Dalibor Petković, Slavica Cvetkovic, Evaluation of wind turbine noise by soft computing methodologies: A comparative study, Renewable and Sustainable Energy Reviews, Volume 56, April 2016, Pages 1122-1128.

[25]: I. Hashem, M.H. Mohamed, A.A. Hafiz, Aero-acoustics noise assessment for Wind-Lens turbine, Energy Volume 118, 1 January 2017, Pages 345-368

[26]: Nicolas Noiray, Bruno Schuermans, Deterministic quantities characterizing noise driven Hopf bifurcations in gas turbine combustors, International Journal of Non-Linear Mechanics, Volume 50, April 2013, Pages 152-163.

[27]: Craig A. Wilson, State of the art-gas turbine noise control, The Journal of the Acoustical Society of America April 1974 55(S1)

[28]: Louis A. Challis and Associates Pty. Ltd, Gas turbine noise control, The Journal of the Acoustical Society of America (1979) 65, S104

[29]: R. M. Hoover, Noise Control For Gas Turbine Installations, The Journal Of The Acoustical Society Of America (1973) 54, 289.

[30]: Frank J. Heymann ,Michael A. Staiano, Steam Turbine Control Valve Noise, The Journal Of The Acoustical Society Of America (1973) 54, 289.

[31]: R. M. Hoover, Low Frequency Noise Of Gas Turbines, The Journal Of The Acoustical Society Of America (1973) 53, 386.

[32] : J. R. Cummins Jr., Gas Turbine Power Plant Noise Source Identification Using Contours, The Journal Of The Acoustical Society Of America (1979) 65, S105.

[33] :Richard R. Audette, Gas Turbine Exhaust Silencer Self Noise, The Journal of the 
Acoustical Society Of America (1974) 55, 414

[34]: Ramani Ramakrishnan And Eric D. Wilson, Numerical Methods For Gas Turbine Silencer Design, The Journal Of The Acoustical Society Of America(1995) 98, 2873

[35]: Jonathan Chui, Yong Ma, Salem Hertil, Application Of Barrier In Industrial Noise Control, The Journal Of The Acoustical Society Of America (2005)117, 2386.

[36]: Yasuaki Okada, Koichi Yoshihisa, Kazuki Higashi2;z and Naoto Nishimura, Horizontal directivity of sound emitted from wind turbines, Acoust. Sci. \& Tech. (2016); 37, 5

[37]: Ofelia Jianu, Marc A. Rosen and Greg Naterer, Noise Pollution Prevention in Wind Turbines: Status and Recent Advances, Sustainability (2012); 4, Pages 1104-1117.

[38]: Sayed Abas Ali, Industrial noise levels and annoyance in Egypt, Applied aoustics, Volume 72, Issue 4, March (2011), Pages 221-225.

[39]: Luis Conde Santos, Christine Matias, Frederico Viera, Fatima Valado, Conférence Acoustica 20-22 octobre, université de cimbra portugale, (2008) ; Pages 1-12.

[40] : Rapport de stage de complexe GP1/Z fournit par secrétariat de département de sécurité industriel et environnement du complexe GP1/Z.

[41] : Centre d'études sur les réseaux, les transports, l'urbanisme et les constructions publiques françaises, catalogue des logiciels de calcul du bruit des infrastructures routières et ferroviaires, un aperçu du marché français, Mai 2002.

[42]: DEFRA. Towards a national ambient noise strategy. A consultation paper from the air and environmental quality division; 2001

[43]: Kang-Ting Tsai a, Min-Der Lin b, Yen-Hua Chen b, Noise mapping in urban environments: A Taiwan study, Applied Acoustics, 70 (2009) 964-972

[44]: Tarık SerhatBozkurt, Sevtap Y1lmazDemirkale, The field study and numerical simulation of industrial noise mapping, Journal of Building Engineering, Volume 9, January 2017

[45]: Peters,R.J.,Smith,B.J, Hollins .M., Acoustics and Noise Control, 3rd edition, Pearson Education Limited. (2011)

[46]: ISO 1996-1:1981, Acoustics-Description and measurement of environmental noise, Part 1: Basic quantities and procedures. 
[47] : Shatha AJ. Ibrahi, Noise Mapping of the Campus of the College of Engineering /The University of Al-Mustansiriyah, Vol.5, No.4, 2015

\section{How to cite this article:}

Arbaoui I, Hamou A, Abderrahim H, Tayeb A, Sayad N, Arbaoui A. Comparative study of the noise generated by the moto-compressor and that generated by the turbo-compressor. J. Fundam. Appl. Sci., 2018, 10(1), 201-215. 